\title{
PSYCHOLOGICAL CHARACTERISTICS OF SURGEONS IN A STATE OF OCCUPATIONAL STRESS
}

\author{
Nilufar Rasulova ${ }^{1}$
}

\begin{abstract}
The article describes the stress resistance of surgeons. Several types of doctors' identities have been identified that determine the features of his communication and relationships with patients. The study allows us to identify and study methods for measuring and analyzing the psychophysical workloads of male surgeons.
\end{abstract}

Key words: emotional stability, empathy, affiliation, stress management, manager, Islamic sources, psychological analysis, Islamic psychology.

doi: http://doi.org/10.15350/L_2/5/51

Согласно должностной инструкции на должность врача-хирурга назначается лицо, имеющее высшее медицинское образование и прошедшее подготовку по специальности "Хирургия". В силу своей должностной обязанности врач хирург должен знать: методы и правила оказания лекарственной и неотложной медицинской помощи; содержание хирургии как отдельной клинической дисциплины; организацию, структуру, задачи, штаты и оснащение хирургической службы; все правовые и нормативные документы по своей специальности; методы по профилактике, диагностике, лечению и реабилитации больного; планирование деятельности и всей отчетности хирургической службы; методику и порядок контроля своей службы. Врач хирург выполняет свои должностные обязанности по инструкции. Его работа сложна и высокой степенью ответственности. За совершенные в процессе проведения лечебных мероприятий правонарушения или бездействие; за ошибки в процессе осуществления своей деятельности, повлекшие за собой тяжкие последствия для здоровья и жизни пациента; а также за нарушение трудовой дисциплины, законодательных и нормативно-правовых актов врач-хирург может быть привлечен в соответствии с действующим законодательством в зависимости от тяжести проступка к дисциплинарной, материальной, административной и уголовной ответственности. В профессиональной деятельности врача хирурга много рабочих нагрузок, которые воздействуют на психоэмоциональное, психофизиологическое, личностное состояние врача. Всегда ли это состояние становится профессиональным стрессом. Деятельность врача хирурга возможно профессиональный стресс возникает в силу наличия рабочих нагрузок и проявляется в повышение реактивной и личностной тревожности, что негативно сказывается на реализации умственного потенциала. В результате исследования были выделены следующие характеристики:

1.квалификация, опыт и искусство врача;

2.плохое знание психологии пациента

3.профессиональный статус врача

4.возраст (более старший кажется и более опытным, знающим),

5.внешний вид (солидная комплекция, в очках)

${ }^{1}$ Nilufar Rasulova, Senior teacher, International Islamic Academy, Uzbekistan. 
6.первое впечатление больного о принимающем его или лечащем враче. мимика,

7.жестикуляция,

8.тон голоса,

9.эмпатия

10.проявление к нему симпатии

11.антипатия зависит от переноса эстетического стереотипа.

12.терпение

13.такт,

14.уметь слушать он должен дать больному высказаться о его переживаниях, проблемах, жалобах, опасениях

15.коммуникативные навыки

Манера поведения врача так же может создать напряжение в отношениях, что нейтрализует протекание профессионального стресса. Это когда врач спокоен и уверен, но не надменен, если манера его поведения быстрая, решительная, настойчивая и сопровождается человеческим участием и деликатностью. Этически правильное профессиональное поведение врача, его личные нравственные качества, нравственный облик личности врача. Профессионально значимые качества врача: волевые качества, высокая работоспособность, наблюдательность, коммуникативность, развитость тонкой моторики, мышление. Б. Д. Карвасарский отмечает необходимость наличия у врача коммуникативной компетентности, которая обеспечивает взаимопонимание, доверие в отношениях [1] Наличие у врача коммуникативной компетентности, которая обеспечивает взаимопонимание, доверие в отношениях. Среди психологических характеристик, формирующих коммуникативную компетентность, он выделяет: аффилиацию, эмоциональную стабильность, эмпатию, сензитивность к отвержению. Среди неблагоприятных черт характера (несдержанности, избыточной эмоциональности, замкнутости) проявления тщеславия, недоступности критике, болтливости, злорадства.

Выделяют несколько типов личности врачей, которые определяют особенности его общения и взаимоотношения с больными. Типы врачей по уровню общения с пациентами. [2] Для неуспешных врачей характерны следующие отрицательные особенности: низкая эмпатийность, заниженное отношение к людям как ценности, отрицательная направленность интеракции, игнорирование психологического состояния пациента, отсутствие отношения к пациенту как активному соучастнику лечения, отсутствие готовности прийти на помощь. Такие характеристики как высокая тревожность, глубокая интровертированность, депрессивность, невротические черты личности врача снижают его эффективность и повышают влияние профессионального стресса [3]

Возможно, что низкая коммуникативная компетентность снижает стрессоустойчивость. Васильков с соавторами (2001) отмечают, что определяющее значение для выраженности у врачей профессионально важных качеств (ПВК) имеет процесс овладения врачебной специальностью. В связи с этим они отмечают следующие закономерности развития ПВК: наблюдается увеличение значимости качеств мышления; возрастает значение профессиональных умений; снижается значение качеств, определяющих работоспособность в экстремальных условиях. Рабочие нагрузки влияют на повышение тревожности, что отражается на продуктивности деятельности и на качество общения. Некомпетентность в свою очередь затрудняет взаимодействие с пациентом, что негативно сказывается на продуктивности деятельности врачей.

Проблема заключается в том, что в больницах отсутствует психологическая 
служба, где были бы обустроены комнаты психологической разгрузки для хирургов, либо наличие комнат для отдыха с специальной обстановкой и наличным массажным креслом. Развитие техники, создание автоматизированных систем управления, автоматизация и механизация производственных процессов существенным образом изменили характер труда человека. Основными его задачами становится контроль процессов управления, принятия решений в нестандартных ситуациях, дублирование техники и т.д., Казалось бы, более совершенная техника должна значительно облегчить труд человека. С одной стороны, так оно и есть, но с другой исследования психологов, физиологов, социологов, эргономистов свидетельствуют в ряде случаев об обратном. Проблема взаимодействия врача хирурга в условиях профессионального стресса стала одной из основных проблем современной науки.

Проведенное исследование позволяет выявить и изучить методы измерения и анализа психофизических рабочих нагрузок мужчин врачей хирургов. Экстремальные условия деятельности часто предъявляют повышенные требования к врачам. Из всех субсиндромов (когнитивного, эмоционально-поведенческого, социально-психологического, вегетативного) у врачей наиболее выражен вегетативный субсиндром стресса. Этот субсиндром проявляется в возникновении либо тотальных, либо локальных физиологических стрессовых реакций, которые имеют адаптационную сущность, но могут становиться основанием для развития так называемых болезней стресса. В этом случае может быть и речь идет о повышенной тревожности и психоэмоционального напряжения.

Возможность использования комплекса психологических методов и методик, основанных на методологии общей, инженерной и дифференциальной, организационной психологии и психофизиологии позволяет повысить качество практической реализации деятельности организационного психолога. На основание исследования была составлена «Психологические характеристики врачей хирургов в ситуации профессионального стресса». Исследование показало, что для испытуемых врачей-хирургов в состоянии профессионального стресса при определении целей своей профессиональной деятельности характерно стремление к конкуренции, достижению цели, но при этом они быстро отказываются от цели. При распределении времени у них проявляются цепные реакции физических и умственнопсихических нарушений, из-за чего они вынуждены часть своих ресурсов тратить на борьбу с негативными психологическими состояниями, возникающими в процессе стресса (в том числе с тревожностью). Очень чувствительны к нагрузкам Выявлена низкая стрессоустойчивость, что делает их уязвимыми для стресса. Не владеют навыками преодоления стресса и повышения стрессоустойчивости.

Обычно не удовлетворены собой и обстоятельствами. Вынуждены большую часть своих ресурсов тратить на борьбу со стрессом, часто проявляют агрессивность, нетерпеливость, отстраненность. Эти испытуемые затрудняются с выбором стратегии борьбы со стрессом. Они не владеют аутотренингом, медитацией, дыхательными упражнениями, мышечной релаксаций. Но выражают желание овладеть. Среди реально используемых испытуемыми приемов снятия стресса выделены: сон, общение с друзьями, общение с членами семьи, алкоголь, курение, еда, перерыв в работе, секс, хобби, физическая активность. В каждом случае предпочтения индивидуальные.

В отличии от этой группы испытуемых врачи хирурги с высоким уровнем стрессоустойчивости точно определяют цели и пути их достижения, умеют рационально распределять время, могут долгое время работать с большим напряжением сил. Неожиданности, как правило, не выбивают их из колеи. Сильные потрясения 
воспринимают, как урок в жизни и включают механизмы самооценки и значимости. Круг их интересов достаточно широк. Уверены в себе. Умеют проявлять свои сильные стороны и быстро восстанавливать своё психическое состояние.

Выявленные психологические характеристики представляют интерес для психологов работающих в сфере медицинских услуг и при профессиональной подготовке врачей хирургов неотложной помощи. В своей работе мы остановимся лишь на профилактике профессионального стресса, методы рассчитаны на врачей. Первый шаг работы заключается в диагностике и построении беседы с целью осознания своего состояния. Вторая часть рассмотрения способа разрешения проблемы и поиск путей индивидуального более эффективного варианта решения проблем профессионального стресса и его негативного воздействия. Главное не останавливаться в достижении результатов независимо от эффекта метода. Нужно подбирать индивидуальные конструктивные методики повышения стрессоустойчивости. Особенно когда речь идет о негативном воздействие рабочих нагрузок на состояние врача. Под рабочими нагрузками мы понимаем все составные, которые описали в экспериментальной части исследования. Гипотеза доказана на $\mathrm{R}=0.69$.

\section{References}

[1] B. D. Karvasarsky. Clinical Psychology., - М. 2004 год

[2] Konechniy R., M. Boukhal. Psychology in medicine. Prague: Avicenum,1983. - 405 c.

[3] Schwartzzeid E. E. The identity of the dentist $\bullet$ as a factor in the therapeutic effect on patients / E.E. Schwartzzeid // Dentistry. 1994. — № 1. - C. 46-48. 